\title{
Bradykinin-induced bronchospasm in the rat in vivo: a role for nitric oxide modulation
}

\author{
T. Homma*, C.G. Irvin**
}

\begin{abstract}
Bradykinin-induced bronchospasm in the rat in vivo: a role for nitric oxide modulation. $T$. Homma, C.G. Irvin. C) ERS Journals Ltd 1999.

ABSTRACT: Bradykinin has an important role in asthma pathogenesis, but its site of action is unclear. It was previously reported by the authors that bradykinin causes a dose-dependent reduction in dynamic compliance but little change in total lung resistance. This suggested that bradykinin may have a preferential effect in the distant lung. The purpose of the current investigation was to better characterize the effects of bradykinin on pulmonary resistance in rodents and explore the role of nitric oxide release in modulating the effect of bradykinin.

Airway constriction was induced in the rats by aerosol administration of bradykinin with or without treatments with the inhaled bradykinin-2 receptor antagonist, Hoe 140 or the nitric oxide synthase inhibitors $N^{G}$-nitro-L-arginine methylester or $N^{G}$ monomethyl-L-arginine. Total lung resistance was partitioned into tissue and airway resistance by using the alveolar capsule method.

Bradykinin induced a significant increase in both resistances. Hoe 140 abolished the response to bradykinin. The nitric oxide synthase inhibitors enhanced the bronchoconstricting response.

In conclusion, the bradykinin response in the rats was not only localized to conducting airways but also involved a relatively selective tissue reaction. Bradykinininduced bronchospasm in the rat is solely due to activation of bradykinin-2 receptor. Further, it was shown that nitric oxide significantly modulates the bronchospasm caused by bradykinin, suggesting that nitric oxide is an important modulator of airways responsiveness to bradykinin.

Eur Respir J 1999; 13: 313-320.
\end{abstract}

\begin{abstract}
*Division of Respiratory Disease, Institute of Clinical Medicine, University of Tsukuba, Tsukuba, Ibaraki, Japan. **Division of Pulmonary Sciences and Critical Care Medicine, Dept of Medicine, National Jewish Medical Research Center and Division of Pulmonary Sciences University of Colorado Health Science Center, Denver, Colorado, USA.
\end{abstract}

Correspondence: T. Homma

Division of Respiratory Disease

Institute of Clinical Medicine

University of Tsukuba

Tsukuba

Ibaraki, $305-8575$

Japan

Fax: 81298533144

Keywords: Airways

bradykinin

hyperresponsiveness nitric oxide

rat

Received: March 311998

Accepted after revision October 111998
Bradykinin is a nine amino acid peptide that has a number of properties appropriate to an inflammatory mediator of asthma [1]. Potentially, bradykinin has an important role in asthma pathogenesis based on several lines of evidence. Firstly, asthmatic patients have elevated kinin concentrations in plasma, as well as nasal and bronchoalveolar lavage fluid after antigen challenge [2]. Of particular interest is the observation that inhaled bradykinin causes bronchoconstriction in asthmatic subjects but not in normal subjects [3]. In addition, the authors have previously shown that, in the rat, bradykinin was necessary but not sufficient for the increase in airways responsiveness caused by cationic proteins [4]. A recent study by RICCIARDOLO et al. [5] in humans shows that the nitric oxide inhibitor $N^{\mathrm{G}}$-monomethyl-L-arginine (L-NMMA) enhances the response to inhaled bradykinin in humans, suggesting that the airway responses to bradykinin is significantly modulated by nitric oxide.

The authors have previously shown that, in the rat, bradykinin was a poor bronchoconstrictor and only caused significant changes in dynamic compliance [4]. Changes in dynamic compliance suggest a peripheral site of action for bradykinin, and further, it would make bradykinin a unique bronchoconstrictor in this regard [6, 7]. It has also been shown that bradykinin elicits NO release in the airways of animals, which can modulate airways smooth muscle function [8-13]. The purpose of the current investigation was firstly to better describe the site of action of bradykinin in the lung and secondly, to explore the role of nitric oxide release in modulating the bradykinin effects. It was postulated that the relatively weak bronchoconstriction observed with bradykinin compared to methacholine might be explained by either site of action in the axial dimension along the airway tree or intrinsic NO formation, which would counteract the airways response to bradykinin.

\section{Methods}

Male Sprague-Dawley rats free of common pathogens were obtained. Sixty-six animals, 20-30 weeks old, weighing $305.4 \pm 11.2 \mathrm{~g}$ (mean \pm SEM) were used in this study. Studies were performed under an institutionally approved protocol and follow the Animal Welfare Act of 1984. Pentobarbital sodium $\left(70 \mathrm{mg} \cdot \mathrm{kg}^{-1}\right)$ was injected intraperitoneally to achieve adequate anaesthesia. Maintenance of anaesthesia was achieved with additional doses of pentobarbital, equivalent to one-third of the initial dose, and were given on a regular basis.

A snugly fitted tracheal cannula (PE-240: $1.67 \mathrm{~mm}$ i.d., 2.42 o.d. and $25 \mathrm{~mm}$ in length; Clay Adams, Parsippay, NJ, USA) was placed into the trachea following a 
tracheostomy. The rats were mechanically ventilated with a volume ventilator (model 683; Harvard Apparatus, South Natick, MA, USA) with a tidal volume of $10 \mathrm{~mL} \cdot \mathrm{kg}^{-1}$, 60 breaths $\cdot \mathrm{s}^{-1}$, and at a positive end-expiratory pressure (PEEP) of $0.49 \mathrm{kPa}$. A femoral venous line was placed for fluid administration, and intravenous saline was administered at a rate of $1.5 \mu \mathrm{mol} \cdot \mathrm{min}^{-1}$. To prevent cooling of the body, the rats were then placed on a warming pad. A heated pneumotachograph (model 8410; Hans Rudolph, Kansas City, MO, USA) was attached to one end of the tracheal tube to measure airflow. The pressure across the two parts of the pneumotachograph was measured with a differential pressure transducer (MP-45; $\pm 0.196 \mathrm{kPa}$, Validyne Engineering Co, North Ridge, CA, USA). The resistance of the tracheal cannula was linear up to flow rates of $256.5 \mathrm{mmol} \cdot \mathrm{min}^{-1}$, determined to be $3.92 \mathrm{kPa} \cdot \mathrm{L} \cdot \mathrm{min}^{-1}$ and subtracted so that the reported results represented intrinsic resistance. Volume was obtained by digital integration of the signal from the pneumotachograph.

As previously described $[6,7,14]$ an alveolar capsule was used to measure regional alveolar pressure $(P \mathrm{~A})$. Briefly, an alveolar capsule was made out of the distal extremity of a $3-\mathrm{mL}$ syringe. The thorax was split open, widely retracted by means of a midline sternotomy. The flat surface of the alveolar capsule was glued to the pleural surface using cyanoacrylate glue (Super Glue, Loctite, Cleveland, $\mathrm{OH}$, USA). The pleura was then punctured with an electrocautery needle to measure $P$ A.

The validity of the pressure measurement from the alveolar capsule method was confirmed for each experiment using the following criterion. If $P$ A was behind a closed airway, the $P$ A may remain unchanged or even fall as lung volume increases. Another situation is where air leaks around the capsule or blood within the alveoli diminished the amplitude of the PA swing compared to airway opening pressure $(P \mathrm{ao})$. The criteria used in this study are: 1$)$ the magnitude of the PA swing matches the tracheal pressure $(P$ tr $)$ swing during slow tidal ventilation; 2$)$ lung elastance $(E \mathrm{~L})$ estimated from $P$ tr is within $10 \%$ of that estimated from $P \mathrm{~A}$; and 3$)$ tissue resistance $(R \mathrm{ti})$ as determined from two alveolar capsules is within $15 \%$ of each. If all three criteria were met, the capsules were considered to be successfully installed. The alveolar capsule patency was ascertained every $300 \mathrm{~s}$. A $12 \%$ failure rate was experienced: these data were not reported.

Bradykinin (Sigma Chemical Co., St. Louis, MO, USA) was stored desiccated at $-20^{\circ} \mathrm{C}$. A stock solution of 10 $\mathrm{mg} \cdot \mathrm{mL}^{-1}$ in saline was prepared fresh on the day of study, and serial dilutions were made with bacteriostatic, buffered $0.9 \%$ saline. Control nebulizations were performed using the same saline. Baseline measurement were obtained after surgical preparation, a stable ventilation pattern was established, and leaks (end-inspiratory breath holding) were evaluated. A total lung inflation (peak inspiratory pressure of $1.96 \mathrm{kPa}$ ) was performed twice so as to standardize volume history. After a 120 -s stabilization period, baseline recordings $(30 \mathrm{~s}$ in duration each at a PEEP of $0.49 \mathrm{kPa}$ ) were sampled three times $300 \mathrm{~s}$ apart.

\section{Protocols}

Bradykinin challenge. Rats were challenged with aerosols of bradykinin with the following method. The nebulizer system was switched into the inspiratory arm of the ventilatory circuit. An aerosol was generated by an ultrasonic nebulizer that produces particles with a mean aerodynamic diameter of $3.0 \mu \mathrm{m}$ (Porta-Sonic model 8500C,: DeVilbiss Health Care, Somerset, PA, USA) and delivered into the airway for $30 \mathrm{~s}$ at a flow rate of $8.91 \mathrm{mmol} \cdot \mathrm{min}^{-1}$. Baseline measurements were followed by aerosolized $0.9 \%$ saline and serial administration of progressive half-log increment concentrations of aerosolized bradykinin ranging $0.1-10.0 \mathrm{mg} \cdot \mathrm{mL}^{-1}$ or until a maximum increase in total lung resistance $(R \mathrm{~L})$ was observed. When there was no obvious reaction to challenge, measurements were taken $300 \mathrm{~s}$ after an aerosolization. After observing a constrictor response, subsequent doses were not administered until resistance and elastance had returned to within $10 \%$ of baseline on two consecutive readings. A total lung inflation was performed before each aerosol delivery to standardize lung-volume history. During the course of the experiment, $P$ tr was continuously monitored. From these data, bradykinin dose-response curves were assembled.

Bradykinin-2 receptor blockade. The response of the airways to bradykinin was determined after airway inhalation of a specific $\beta_{2}$-receptor antagonist, Hoe 140 . Hoe $140(0.1,1.0,10 \mathrm{nmol}$, for each $\mathrm{n}=6)$ treatments were accomplished by aerosol delivery through the endotracheal tube. An aerosol was generated by the same ultrasonic nebulizer and delivered into the airway for 30 $\mathrm{s}$ at a flow rate of $8.91 \mathrm{mmol} \cdot \mathrm{min}^{-1}$ before $30 \mathrm{~min}$ exposure to aerosolized bradykinin.

Nitric oxide synthase blockade. The nitric oxide synthase (NOS) inhibitors, $N^{\mathrm{G}}$-nitro-L-arginine methyl ester (L-NAME) or L-NMMA were employed to antagonize the ability of NOS to generate NO. L-NAME or LNMMA or saline sham treatments were administered as follows. After an equilibration period of $120 \mathrm{~s}$, the rat inhaled 10 breaths of an aerosol containing: 1) L-NAME (either 1.2 or $2.4 \mathrm{mmol}$ ), 2) L-NMMA (either 1.2 or 2.4 $\mathrm{mmol}$ ) or 3) saline. This procedure was repeated every $300 \mathrm{~s}$ for $30 \mathrm{~min}$ (total of 60 breaths). A bradykinin dose-response curve was then determined. Five groups of animals were studied: a saline vehicle group $(n=6)$; two doses of L-NAME of $1.2(n=6)$ mmol and $2.4(n=6)$ mmol; and two doses of L-NMMA of $1.2(n=6) \mathrm{mmol}$ and $2.4(\mathrm{n}=6) \mathrm{mmol}$.

Bradykinin, L-NAME, and L-NMMA were purchased from Sigma Chemical Co. and prepared in saline. Hoe 140 was synthesized in the pharmaceutical department of Hoechst-Roussel Pharmaceuticals and was kindly donated by K.J. Wirth (Frankfurt, Germany). Hoe 140 was freshly dissolved each day in saline.

\section{Data analysis and calculations}

$R \mathrm{~L}$ and $E \mathrm{~L}$ were calculated during mechanical ventilation using the following equation:

$$
P \operatorname{tr}(\mathrm{t})=V^{\prime}(\mathrm{t}) \times R \mathrm{~L}+V(\mathrm{t}) \times E \mathrm{~L}+K .
$$

where $P \operatorname{tr}(\mathrm{t})$ is the tracheal pressure, $V^{\prime}(\mathrm{t})$ the flow, $V(\mathrm{t})$ the volume, and $K$ a constant whose value is estimated by multiple linear regression. $R \mathrm{~L}, E \mathrm{~L}$ and $K$ were calculated by multiple linear regression fitted breath-by-breath. 
$R$ ti was calculated during mechanical ventilation for each $P A$ by multiple linear regression from the following equation:

$$
P \mathrm{~A}(\mathrm{t})=V^{\prime}(\mathrm{t}) \times R \mathrm{ti}+V(\mathrm{t}) \times E \mathrm{~L}+K .
$$

Airway resistance (Raw) was calculated by subtracting $R$ ti from $R \mathrm{~L}$, i.e.

$$
R \mathrm{aw}=R \mathrm{~L}-R \mathrm{ti}
$$

The values of $R \mathrm{~L}$ and $R \mathrm{ti}$ were accepted only if the values of $E \mathrm{~L}$ obtained from $P \mathrm{~A}-P$ ao or $P$ ao-atmospheric pressure $(P$ atm $)$ were similar $( \pm 10 \%)$, and the $K$ from $P$ A- $P$ ao pressure drop and $K$ from $P$ ao- $P$ atm pressure drop were similar as well as similar to $( \pm 10 \%)$ the real value of PEEP (i.e. $0.49 \mathrm{kPa}$ PEEP). The provocative concentration causing a $150 \%$ increase in values from baseline (PC150) was obtained through linear interpolation of the response plotted on a $\log$ scale and used as an index of airway hyperresponsiveness. The provocative concentrations of bradykinin required to increase $R \mathrm{~L}, R \mathrm{ti}, R \mathrm{aw}$ and $E \mathrm{~L}$ to $150 \%$ relative to baseline $(\mathrm{PC} 150, R \mathrm{~L}, \mathrm{PC} 150, R \mathrm{ti}, \mathrm{PC} 150$, aw, $\mathrm{PC} 150, E \mathrm{~L}$ repectively) were obtained. Further, the relative constriction of airways and tissues at a given $R \mathrm{~L}(R \mathrm{aw} / R \mathrm{~L}$ and $R \mathrm{t} \mathrm{i} / R \mathrm{~L})$ were calculated. Data are shown as the mean \pm SEM or, in the case of the PC150 data, the data is presented as a geometric mean.

\section{Statistical methods}

Comparison of physiological parameters among groups, as a function of dose was performed by a two-factor factorial, repeated measurement of analysis of variance (two-factor factorial ANOVA). Comparisons between two samples were performed using unpaired t-tests. Statistical significance was assumed if $\mathrm{p}<0.05$.

\section{Results}

\section{Baseline mechanics and airways response to bradykinin}

Table 1 presents the baseline values for the various mechanical parameters between the various study groups. There are no significant differences (unpaired t-test with Bonferoini correction) between the various treatment groups in the baseline measurements of lung mechanics.

As presented in figure 1 , in these artificially ventilated animals, bradykinin caused a significant (ANOVA; $\mathrm{p}<$

Table 1. - Baseline lung mechanics data

\begin{tabular}{lccccc}
\hline Treatment & $\mathrm{n}$ & $\begin{array}{c}R \mathrm{~L} \\
\mathrm{kPa} \cdot \mathrm{L}^{-1} \cdot \mathrm{s}\end{array}$ & $\begin{array}{c}E \mathrm{~L} \\
\mathrm{kPa} \cdot \mathrm{L}^{-1}\end{array}$ & $\begin{array}{c}R \mathrm{Raw} \\
\mathrm{kPa} \cdot \mathrm{L}^{-1} \cdot \mathrm{s}\end{array}$ & $\begin{array}{c}R \mathrm{ti} \\
\mathrm{kPa} \cdot \mathrm{L}^{-1} \cdot \mathrm{s}\end{array}$ \\
\hline Saline & 6 & $13.7 \pm 0.98$ & $125.4 \pm 8.8$ & $10.8 \pm 0.98$ & $1.96 \pm 0.98$ \\
Hoe 140 & 6 & $12.7 \pm 0.98$ & $128.4 \pm 7.8$ & $10.8 \pm 0.98$ & $1.96 \pm 0.98$ \\
L-NAME & 6 & $14.7 \pm 0.98$ & $154.8 \pm 7.8$ & $13.7 \pm 0.98$ & $1.96 \pm 0.98$ \\
L-NMMA & 6 & $13.7 \pm 0.98$ & $124.5 \pm 8.8$ & $12.7 \pm 0.98$ & $1.96 \pm 0.98$
\end{tabular}

Value are presented as means \pm SEM. L-NAME: $N^{\mathrm{G}}$-nitro-L-arginine-methyl ester; L-NMMA: $N^{\mathrm{G}}$-monomethyl-L-arginine; $R \mathrm{~L}$ : pulmonary resistance; EL: pulmonary elastance; Raw: airway resistance; $R$ ti tissue resistance. a)

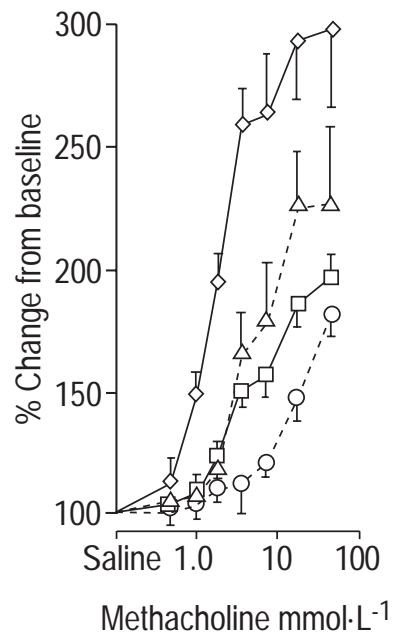

b)

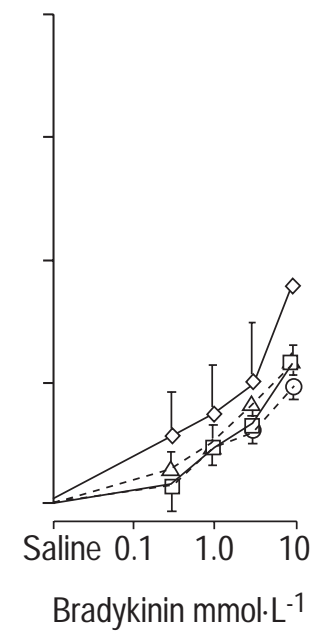

Fig. 1. - Dose-response relationships of partitioned pulmonary resistance to a) methacholine and b) bradykinin. Using alveolar capsules the pulmonary resistance $(R \mathrm{~L})$ is positioned in an airways (Raw) and tissue component $(R \mathrm{ti})$. Bradykinin causes similar changes in $R \mathrm{ti}$ but less of a charge $R \mathrm{~L}$ and Raw response than methacholine, see text for further details. Data (mean \pm SEM) are expressed as a percentage change from the baseline plotted against the log dose of inhaled agonist. $\square: R \mathrm{~L} ; \bigcirc: R$ aw; $\diamond: R \mathrm{ti} ; \Delta$ : lung elastance $(E \mathrm{~L})$. ( $\mathrm{n}=6$ for each agonist.)

$0.01)$ increase in $R \mathrm{~L}, E \mathrm{~L}, R$ aw and $R$ ti. Although the percentage increase in $R \mathrm{ti}$ is the largest observed change, the proportion of $R$ ti to $R \mathrm{~L}$ is only about $14 \%$ and so the contribution of $R$ ti to $R \mathrm{~L}$ is small. Accordingly, the rise in $R \mathrm{~L}$ only just achieves a $150 \%$ change from baseline at the highest dose of bradykinin inhaled.

\section{Role of bradykinin-2 receptors}

If treated prior to the inhalation of bradykinin with a specific bradykinin-2 receptor antagonist (Hoe 140), the response to bradykinin can be inhibited (fig. 2). In this system, this antagonist is very potent and was very effective even at the lowest dose $(0.1 \mathrm{mmol})$ used. Indeed, at the highest dose of Hoe 140, there is virtually no response to bradykinin. It appears that the $R$ ti response is slightly resistant to the effects of this antagonist.

\section{Comparison of bradykinin responsiveness to methacho- line}

When contrasted to the airways response to methacholine (fig. 1, and 3 and table 2), there are some apparent differences in response. Bradykinin appears to be less potent in increasing $R \mathrm{~L}$ than methacholine as the $\mathrm{PC} 150$ is lower (methacholine $4.08 \mathrm{mmol} \cdot \mathrm{L}^{-1}$ versus bradykinin $\left.4.72 \mathrm{mmol} \cdot \mathrm{L}^{-1}\right)$. Moreover, methacholine induces a much larger response in the $R \mathrm{ti}$ than $R$ aw as the ratio of $R \mathrm{ti} / R \mathrm{~L}$ is $0.46 \pm 0.11$ for methacholine in contrast to $0.26 \pm 0.09$ for bradykinin when compared at the same absolute $R \mathrm{~L}(19.6$ $\mathrm{kPa} \cdot \mathrm{L} \cdot \mathrm{min}^{-1}$ ) (fig. 3). At this point in the dose-response curve, the changes in $R \mathrm{~L}, R$ aw and $E \mathrm{~L}$ are similar, whereas $R$ ti is significantly lower, as shown in table 2 . 
a)

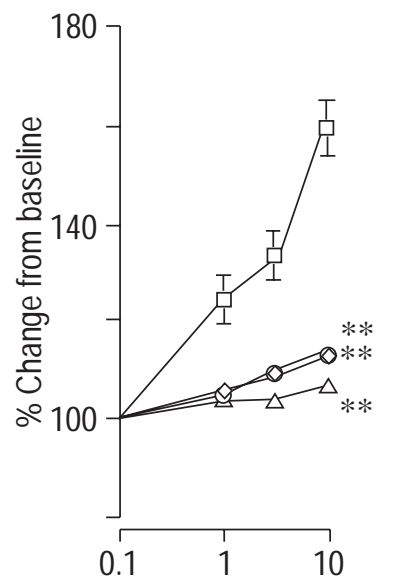

b)

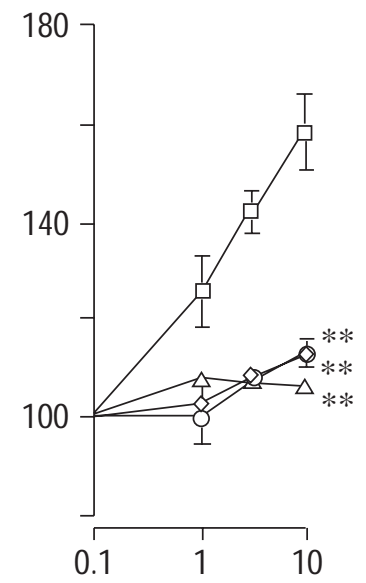

c)

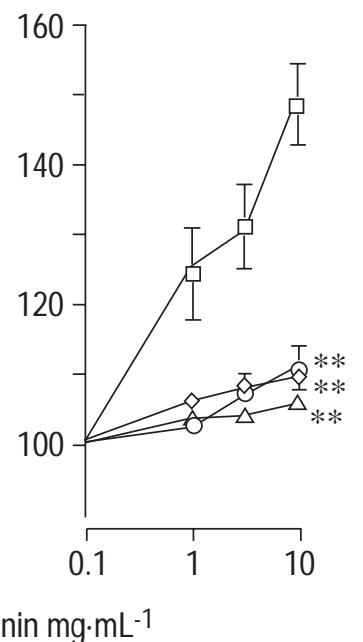

d)

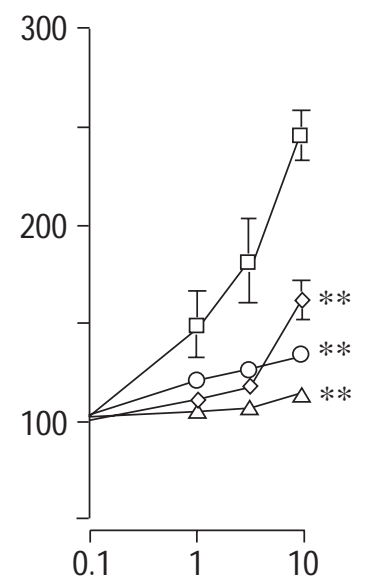

Bradykinin $\mathrm{mg} \cdot \mathrm{mL}^{-1}$

Fig. 2. - Blockade of the bronchoconstrictor response of bradykinin by the selective bradykinin-2 antagonist, Hoe 140 on a) pulmonary resistance, b) lung elastance, c) airway resistance, and d) tissue resistance. Data (mean \pm SEM) are expressed as a percentage change from the baseline agonist concentration of inhaled bradykinin; $\square:$ baseline; $\diamond: 0.1 \mathrm{nmol}$ Hoe $140 ; \bigcirc: 1.0$ nmol Hoe $140 ; \Delta: 10.0$ nmol Hoe 140 . $\mathrm{n}=6$ in each group. $* *$ : $\mathrm{p}<0.01$, ANOVA.

Modulating the effect of nitric oxide on airways response to bradykinin

Figures 4 and 5 present the effects of two different inhibitors of NOS on airways response to inhaled bradykinin. Figure 4 shows the effect of L-NAME on bradykinin-induced bronchoconstriction at two different doses, 1.2 and $2.4 \mathrm{mmol}$. The lower dose of L-NAME (1.2 mmol) did not change the responsiveness measured with $R \mathrm{~L}, E \mathrm{~L}$ or $R$ aw. However, the $R \mathrm{ti}$ response was significantly (ANOVA $\mathrm{p}<0.05$ ) increased, but the $R \mathrm{~L}$ response was only slightly shifted left (fig. $4 \mathrm{a}$ ) because $R$ ti is such a small component of $R \mathrm{~L}$. At the higher dose of $\mathrm{L}-$ NAME, all four parameters were significantly $(R \mathrm{~L}, E \mathrm{~L}$ and $R$ ti $\mathrm{p}<0.01$ and $R$ aw $\mathrm{p}<0.05)$ shifted leftward.

In figure 5 , the modulating effects of L-NMMA on bradykinin-induced airway constriction are presented. Similar to L-NAMA, the higher dose appears to be more effective

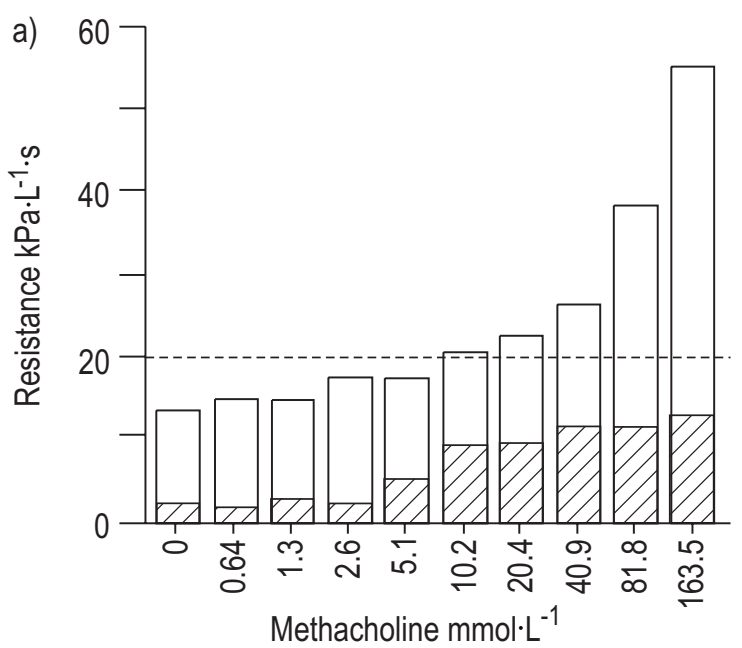

than the lower dose in enhancing the bronchospastic effect of bradykinin. However, there are some differences between the two inhibitors. L-NAME when compared to LNMMA appears to be more effective in enhancing the $R$ aw and hence, the $R \mathrm{~L}$ response.

When airways responsiveness is expressed as a PC150 (table 3), the shifts in the dose response to bradykinin are significant and very similar for both L-NAME and LNMMA. As measured by PC150, the fold increases in responsiveness to inhaled bradykinin ranged $2.7(R \mathrm{~L})$ to $9.5(E \mathrm{~L})$.

To determine whether the less potent response of the lung to bradykinin than methacholine (especially $R \mathrm{ti}$ ) could be accounted for by a modulating role of NO, the $R \mathrm{ti} /$ $R$ aw responses were compared at equivalent increases in $R \mathrm{~L}\left(19.6 \mathrm{kPa} \cdot \mathrm{L} \cdot \mathrm{min}^{-1}\right)$ as shown in figure 6 and table 4 . Even though L-NMMA and L-NAME were found to enhance the bradykinin response (fig. 4 and 5) at equivalent

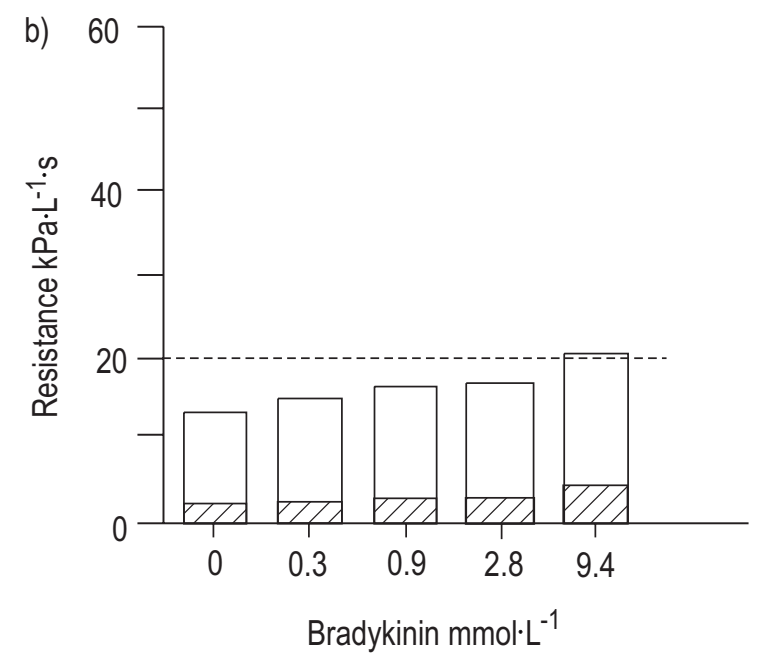

Fig. 3. - Partitioned total pulmonary resistance with a) methacholine and b) bradykinin, where the changes in tissue resistance ( $\mathbb{C})$ and airway resistance $(\square)$ are shown. Data are expressed as absolute resistance $\left(\mathrm{kPa} \cdot \mathrm{L} \cdot \mathrm{min}^{-1}\right) .---:$ comparison at a similar absolute change in resistance $\left(19.6 \mathrm{kPa} \cdot \mathrm{L} \cdot \mathrm{min}^{-1}\right)$. 
Table 2. - A comparison of bradykinin to methacholine for tissue resistance $(R \mathrm{t})$ and airway resistance (Raw) responses when compared at similar increase change in pulmonary resistance $(R \mathrm{~L})$

\begin{tabular}{lcccc}
\hline Treatment & $\begin{array}{c}R \mathrm{~L} \\
\text { \% change }\end{array}$ & $\begin{array}{c}E \mathrm{~L} \\
\text { \% change }\end{array}$ & $\begin{array}{c}\text { Raw } \\
\text { \% change }\end{array}$ & $\begin{array}{c}R \mathrm{ti} \\
\% \text { change }\end{array}$ \\
\hline Methacholine $\left(10.2 \mathrm{mmol} \cdot \mathrm{L}^{-1}\right)$ & $160.5 \pm 10.9$ & $143.7 \pm 20.6$ & $140.7 \pm 11.9$ & $376.4 \pm 47.1$ \\
Bradykinin $\left(9.4 \mathrm{mmol} \cdot \mathrm{L}^{-1}\right)$ & $151.7 \pm 15.4$ & $169.8 \pm 23.2$ & $139.8 \pm 11.6$ & $229.3 \pm 32.3 *$ \\
\hline
\end{tabular}

Value are presented as means \pm SEM as determined at the dose of agonist that increased $R \mathrm{~L}$ to $19.6 \mathrm{kPa} \cdot \mathrm{L}^{-1} \cdot \mathrm{s}$. EL: pulmonary elastance; *: $\mathrm{p}<0.05$ (unpaired t-test) versus saline.

changes in total pulmonary resistance, the proportion of total resistance contributed by tissue resistance still remains small and significantly different from that observed with methacholine.

\section{Discussion}

The results of the current study demonstrate that inhaled aerosols of bradykinin cause a dose-dependent bronchoconstriction in the rat. It was found that the increase in the tissue response is greater than the airways response, showing an axial inhomeogeneity of the response of the airways to bradykinin especially when compared to the airways response to methacholine. As the tissue resistance contribution to total pulmonary resistance is small in the rat, this accounts for the less impressive bronchospasm to bradykinin when compared to inhaled methacholine. As the response in the lung periphery may be due to different mechanisms than an airways response and that this might be mediated by different subclasses of receptors, the effects of a specific $\beta_{2}$ antagonist (Hoe 140) were explored. It was found that this antagonist totally abolished the bradykinin response. As it is well known that bradykinin elicits $\mathrm{NO}$ formation $[11,13]$, the possible modulatory activity of $\mathrm{NO}$ on the bradykinin response in the airways was explored. It was found that NO formation blockade as achieved with either of the L-arginine analogues, L-NAME and L-NMMA enhanced the bronchoconstriction caused by inhaled bradykinin. However, even without the modulatory effect of $\mathrm{NO}$, the bronchospastic response to bradykinin is still not as marked as that observed with methacholine. These data suggest that bradykinin causes bronchospasm preferentially in the distal lung; and solely through the activation of bradykinin-2 receptors. Further, it was also shown that NO functions to ameliorate bradykinin response in the lung.

BARNES [1] has reviewed the current evidence that bradykinin is likely to be involved in asthma pathogenesis. There are two major lines of evidence that implicate a role for bradykinin. Firstly bradykinin elicits many pathophysiological reactions consistent with those observed in asthma. For instance, bradykinin causes bronchospasm, vascular leakage and mucus gland secretion. The action of bradykinin is often indirect as bradykinin causes the release of tachykinins with subsequent activation of C-fibres [15] or modulates neural responses [16] that in turn cause end-organ changes. Most importantly, bradykinin is known to cause smooth-muscle contraction, albeit weakly, and increases pulmonary resistance in animals $[11-13,16]$ and humans $[3,5]$. The second line of evidence for an involvement of bradykinin is a compelling finding of elevated kinin levels in nasal and broncholavage fluid after antigen challenge in animals [17] and in particular, humans [2]. Finally, it has been recently demonstrated in adult patients with chronic asthma that 4 weeks' treatment of bradykinin-2 receptor antagonist (Hoe 140) led to a dose-dependent improvement in objective pulmonary function tests (e.g. forced expiratory volume in one second and peak expiratory flow rate) started between weeks
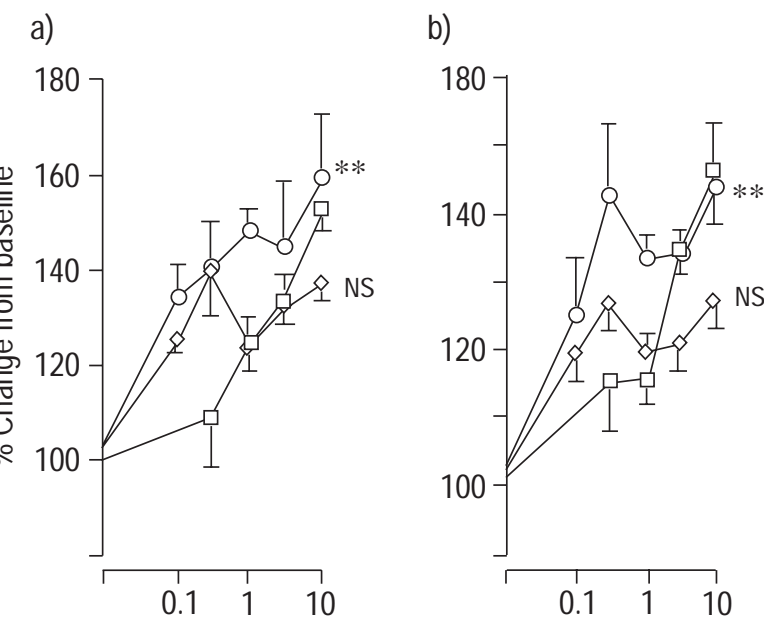

c)

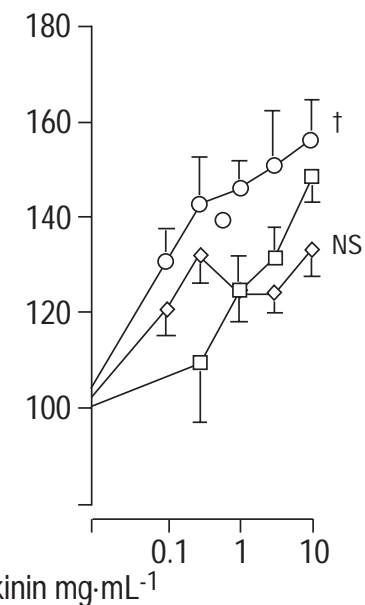

d)

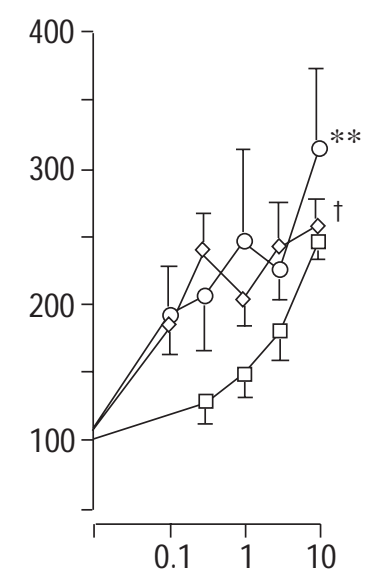

Fig. 4. - Effect of the nitric oxide synthase inhibitor $N^{\mathrm{G}}$-nitro-L-arginine methyl ester (L-NAME) on bradykinin-induced airways response for a) pulmonary resistance, b) lung elastance, c) airway resistance, and d) tissue resistance. Data (mean \pm SEM) are expressed as a percentage change from the baseline plotted against increasing concentration of inhaled bradykinin (log scale). Data are from groups of $n=6$. Two doses of L-NAME were used: 1.2 $\mathrm{mmol}(\diamond)$ and $2.4 \mathrm{mmol}(\bigcirc) . \square:$ baseline. ${ }^{\dagger}: \mathrm{p}<0.5 ; * *: \mathrm{p}<0.01$, ANOVA. 
a)

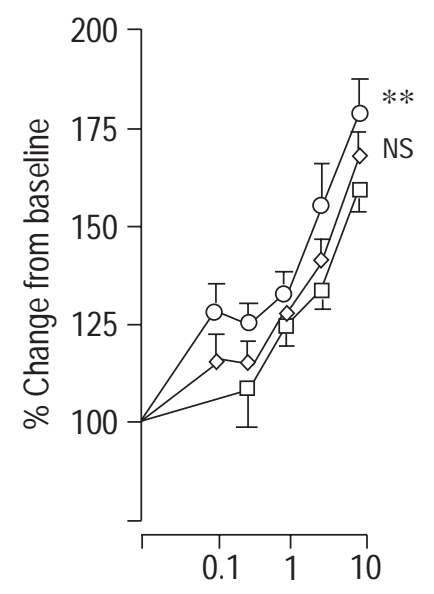

b)

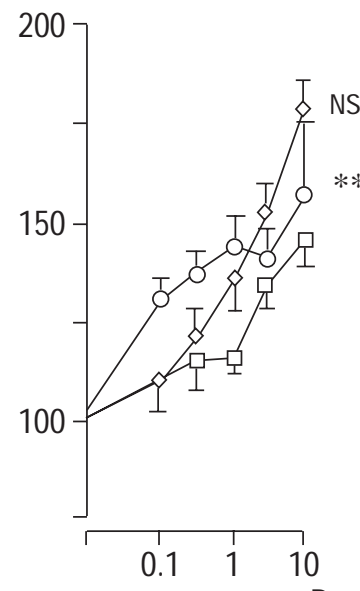

c)

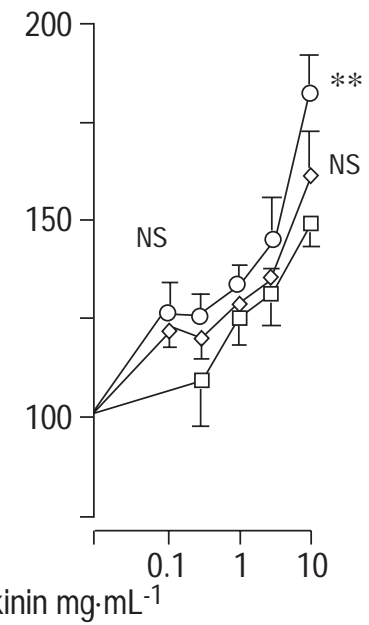

d)

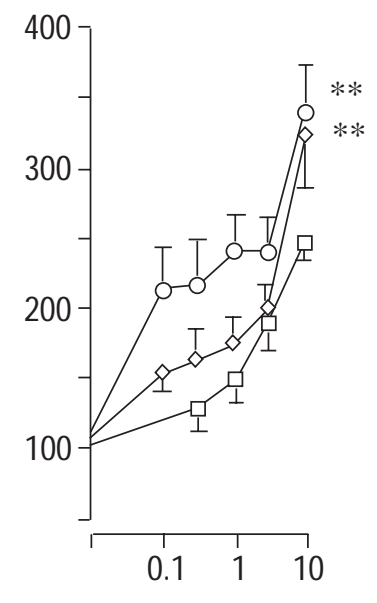

Fig. 5. - Effect of the nitric oxide synthase inhibitor $N^{\mathrm{G}}$-monomethyl-L-arginine (L-NMMA) on bradykinin-induced airways response on a) pulmonary resistance, b) lung elastance, c) airway resistance, and d) tissue resistance. Data (mean \pm SEM) are expressed as a percentage change from baseline plotted against increasing concentration of inhaled bradykinin. Data are from groups of $n=6$. Two doses of L-NMMA were used: $1.2 \mathrm{mmol}(\diamond)$ and 2.4 mmol (○). $\square$ : baseline ${ }^{\dagger}: \mathrm{p}<0.5 ; * *: \mathrm{p}<0.01$, ANOVA.

1 and 2, gradually increased until the end of active treatment and slowly decreased during the placebo run-out phase, suggesting an anti-inflammatory effect of the bradykinin-2 receptor antagonist in asthma [18].

In a previous investigation by the present authors [4] it was observed that bradykinin was a weak bronchoconstrictor as a PC150 for $R \mathrm{~L}$ could not be consistently determined. As a consequence, in that study, the fall in dynamic compliance was needed to assess the effectiveness of a bradykinin antagonist. This finding suggested to the authors that the site of action of bradykinin might be localized axially to the peripheral lung, and it was wondered whether bradykinin might be selective for a response in the parenchyma. In support of this idea, the study of MAK and BARNES [19] using autoradiography localized bradykinin-2 receptors to the endothelium, epithelial cells, nerves and peripheral airways smooth muscle. In addition, a particularly high concentration of receptors were observed within the alveolar wall. The results from the current investigation show that functionally, bradykinin caused an increase in the tissue response, but also a weaker airways response, consistent with the known axial distribution of bradykinin receptor.

Table 3. - Provocative concentrations of bradykinin following treatment with L-NAME $(2.4 \mathrm{mmol})$ or L-NMMA $(2.4$ $\mathrm{mmol}$ )

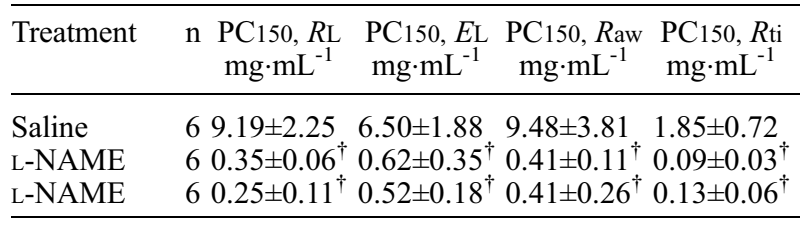

Results are expressed as mean \pm SEM. $\mathrm{PC} 150$ : provocative concentrations of bradykinin required so increase the parameter to $150 \%$ relative of the baseline; L-NAME: $N^{\mathrm{G}}$-nitro-L-argininemethyl ester; L-NMMA: $N^{\mathrm{G}}$-monomethyl-L-arginine; $R \mathrm{~L}$ : pulmonary resistance; $E$ L: pulmonary elastance; $R$ aw: airway resistance; $R$ ti: tissue resistance. ${ }^{\dagger}$ : significantly different from saline ( $\mathrm{p}<$ $0.05)$.
Since determining the peptide sequence of bradykinin in 1960, [1] a number of analogues have been synthesized in order to develop specific and effective bradykinin antagonists. Bradykinin receptors have at least two recognized subclasses. The bradykinin-1 type of receptors for kinins are selective and sensitive to fragments of kinins without the C-terminal arginine (e.g. des-Arg ${ }^{9}$-bradykinin and Lysdes-Arg ${ }^{9}$-bradykinin, also called des-Arg ${ }^{10}$-kallidin), and are found in rabbit isolated blood vessels [1]. Bradykinin2 receptors, where bradykinin is the most potent agonist [1] appears to mediate the vast majority of lung responses. A third subclass of bradykinin receptors, the bradykinin-3 receptor, has been identified by FARMER et al. [20] in the airways smooth muscle of guinea-pigs as there was a residual response following bradykinin-2 blockade. The current study utilized Hoe 140, a bradykinin analogue with increased stability, specificity and potency for the bradykinin-2 receptor [21, 22]. This bradykinin antagonist was very potent in blocking the bronchospasm caused by the inhalation of bradykinin (fig. 2), where the $R \mathrm{ti}$ was slightly more resistant to blockage. This finding confirms that bradykinin-induced bronchospasm is entirely mediated via the bradykinin-2 receptor and does not support a role for other bradykinin receptor subclasses in mediating bronchospasm in this species.

As it is known that 1) bradykinin stimulates NOS activity $[11-13,23,24]$; 2) nonadrenergic inhibition, which is often ascribed to NO, is modulated via bradykinin-2 receptors [16]; and 3) bradykinin is a less potent bronchoconstrictor [4], the possibility that NO modulates the bradykinin response was explored. NOS produces gaseous NO from the amino acid precursor L-arginine and, in the rat, has been spatially localized to nerves and epithelium. [11, 16, 23, 24]. To explore the role of NO in modulating the bronchoconstrictor response to bradykinin, two different inhibitors of NOS: L-NAME and L-NMMA were employed. It was found that both L-arginine analogues L-NAME (fig. 4) and L-NMMA (fig. 5) increased the response to inhaled bradykinin. Also, whereas the shift in the PC150 (table 3) is very similar between the agents, a 


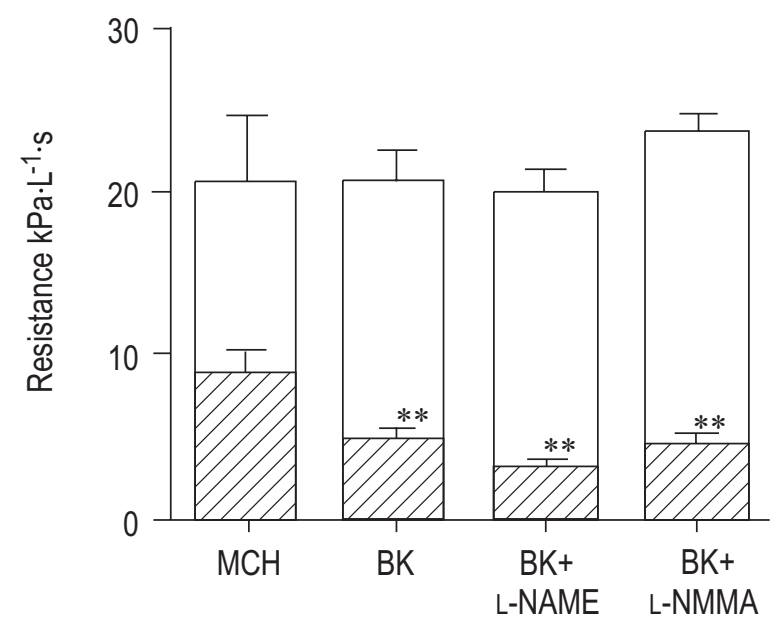

Fig. 6. - Comparison of the partitioned changes in airway resistance $(\square)$ and tissue resistance $(\mathscr{Z})$ caused by methacholine $(\mathrm{MCH})$ at 10.2 $\mathrm{mmol} \cdot \mathrm{L}^{-1}$ or bradykinin $(\mathrm{BK})$ at $9.4 \mathrm{mmol} \cdot \mathrm{L}^{-1}$, which causes similar absolute changes in pulmonary resistance $\left(R \mathrm{~L} ; 19.6 \mathrm{kPa} \cdot \mathrm{L} \cdot \mathrm{min}^{-1}\right)$. The proportional response to $\mathrm{BK}$ is also presented following treatment with the nitric oxide synthase (NOS) inhibitor $N^{\mathrm{G}}$-nitro-L-arginine methyl ester (L-NAME; $2.4 \mathrm{mmol}$ ) or $N^{\mathrm{G}}$-monomethyl-L-arginine (L-NMMA; $2.4 \mathrm{mmol}$ ). Following the treatment with NOS inhibitors, the amount of BK required to increase $R \mathrm{~L}$ to $19.6 \mathrm{kPa} \cdot \mathrm{L} \cdot \mathrm{s}^{-1}$ is less; $\mathrm{L}-\mathrm{NAME}: 1 \mathrm{mg} \cdot \mathrm{mL}^{-1}$ BK and L-NMMA: $3 \mathrm{mg} \cdot \mathrm{mL}^{-1} \mathrm{BK}$. Data are mean \pm SEM. $* *: \mathrm{p}<0.01$ unpaired t-test comparing the three $\mathrm{BK}$ challenges to $\mathrm{MCH}$.

comparison of figure 4 with figure 5 shows that L-NAME appears to be more effective in increasing Raw responses (and hence $R \mathrm{~L}$ responses). It was therefore concluded that the activity of NOS modulates the airways responsiveness to inhaled bradykinin to decrease the resultant bronchoconstriction.

The role of NO in modulating airways responsiveness has been studied before [11-13], but the conclusions reached have been somewhat controversial. Blockage of NO has been shown by KIPS et al. [10] to modulate lipopolysaccharide (LPS)-induced airways hyporesponsiveness but not the transient hyperresponsiveness in rats. In guinea-pigs, NiJKAMP et al. [8] have shown that histamine responsiveness can be augmented by NOS blockade. Furthermore, RICCIARDOLO et al. [13] showed that NOS blockade increases the bronchial responsiveness to inhaled bradykinin and, to a lesser extent, to methacholine in mild asthma, and suggest that some mediator-specific response is involved in releasing bronchoprotective NO. However, KIPS et $a l$. [10] did not find any effect of L-NAME given intravenously on responsiveness to intravenous carbacol and accordingly concluded that NO does not modulate basal

Table 4. - The tissue resistance $(R \mathrm{ti})$ and pulmonary resistance $(R \mathrm{~L})$ ratios at similar levels of bronchoconstriction $\left(19.6 \mathrm{kPa} \cdot \mathrm{L}^{-1} \cdot \mathrm{s}\right)$

\begin{tabular}{lc}
\hline Treatment & $R$ ti $/ R$ L ratio \\
\hline MCH & $0.46 \pm 0.11$ \\
BK & $0.26 \pm 0.09^{\dagger}$ \\
L-NAME + BK & $0.18 \pm 0.13^{\dagger}$ \\
L-NMMA + BK & $0.23 \pm 0.11^{\dagger}$ \\
\hline
\end{tabular}

Results are expressed as mean \pm SEM. MCH: methacholine; BK: bradykinin; L-NAME: $N^{\mathrm{G}}$-nitro-L-arginine-methyl ester; L-NMMA: $N^{\mathrm{G}}$-monomethyl-L-arginine. airways responsiveness in the rat. There are a number of important differences between this latter study and the present study. Firstly, in the present study L-NAME was administered as an aerosol that might be expected to be a better means of blocking epithelial and neural NOS. Further, bradykinin was also given as an aerosol, which likewise could be envisioned to be more likely to cause NOS activation within the epithelium. Accordingly, it was concluded that NOS does, in fact, have an important modulating role in airways responsiveness to bradykinin.

NOS can be functionally characterized as either constitutive (cNOS) or inducible (iNOS), and at least three isoforms exist; the neural NOS and epithelial NOS are constitutive and regulated by $\mathrm{Ca}^{2+} /$ calmodulin, whereas the inducible form is not regulated by $\mathrm{Ca}^{2+}$ or calmodulin and has a high rate of NO production. As the time course of the experiment is relatively short, iNOS may not be as involved in the present system, although this possibility was not directly addressed. Each NOS is thought to have a complex control and possesses a unique profile of response to inhibitors. In particular, endothelial cell NOS is not inactivated by L-NMMA [25], whereas, L-NMMA has been shown to inactivate both iNOS and cNOS. ForSTERMANN et al. [26] have shown that cNOS is more effectively inhibited by L-NAME, whereas iNOS appears to respond better to L-NMMA. In several other systems and species $[8,9,27,28]$ it has been shown that L-NAME is generally more potent than L-NMMA, especially in situations involving epithelial-dependent mechanisms. Thus, for example, NIJKAMP et al. [8] have shown similar differences between L-NAME and L-NMMA in the increase in pulmonary resistance following histamine infusion in the guinea-pig where L-NAME caused a larger increase in responsiveness. As the distribution of cNOS is more central [29], it was predicted that modulating cNOS might be expected to effect the $R$ aw response more than the $R \mathrm{ti}$ response. The patient data show that L-NAME is more potent in affecting an increase in Raw which is consistent with the location in situations involving action of cNOS to conducting airways [29].

It was originally speculated by the present authors that the relatively poorer response of the airways of the rat to inhaled bradykinin might be due to the modulating role of NO. Although it was shown that blocking NOS increases the responsiveness to bradykinin, it was not thought that this completely accounted for the observed differences between bradykinin and methacholine. As expressed in table 4 and figure 6 , it is shown that, even with NO blockade, the increase in $R \mathrm{ti}$ as a portion of $R \mathrm{~L}$ at comparable levels of bronchoconstriction was not as large as the increase in $R \mathrm{ti}$ caused by methacholine. The more likely explanation for the difference between the two agonists is the axial location of the receptors as it is known that acetylcholine receptors have a more central location [30], whereas bradykinins are more peripheral [21].

In conclusion, it has been shown that bradykinin induces an increase in airways resistance as well as tissue responses and that the change in tissue responses was larger than that in the airways. The latter shows that like methacholine [14], the response was not localized to conducting airways but also involves a tissue reaction; however, unlike methacholine, the response to bradykinin was less in the conducting airways. Using a specific antagonist, it was shown that bradykinin-induced bronchospasm in the rat is due to 
activation of bradykinin-2 receptors without any evidence of a residual effect that could be ascribed to other bradykinin receptor subclasses. Further, it was also shown that nitric oxide significantly modulates the bronchospasm caused by bradykinin-induced bronchospasm, as L-arginine analogues, increased the response, suggesting that nitric oxide is an important modulator of airways responsiveness. Lastly, these findings show through direct measurements that the magnitude of the bronchospastic effect of a bronchoconstricting agent can be significantly influenced by the axial site of action within the airway tree.

\section{References}

1. Barnes PJ. Bradykinin and asthma. Thorax 1992; 47: 979-983.

2. Christiansen SC, Proud D, Cochrane CG. Detection of tissue kailikrein in the bronchoalveolar lavage fluid of asthmatic subjects. J Clin Invest 1987; 79: 188-197.

3. Fuller RW, Dixon CMS, Cuss FMC, Barnes PJ. Bradykinin induced bronchoconstriction in humans. Am Rev Respir Dis 1987; 135: 176-180.

4. Coyle AJ, Ackerman SJ, Burch R, Proud D, Irvin CG. Human eosinophil-granule major basic protein and synthetic polycations induce airway hyperesponsiveness in vivo dependent on bradykinin generation. J Clin Invest 1995; 95: 1735-1740.

5. Ricciardolo FLM, Geppetti P, Mistretta A, et al. Randomised double-blind placebo-controlled study of the effect of inhibition of nitric oxide synthesis in bradykinininduced asthma. Lancet 1996; 348: 374-377.

6. Romero PV, Ludwig MS. Maximal methacholine-induced constriction in rabbit lung: interactions between airways and tissue? J Appl Physiol 1991; 70: 1044-1050.

7. Ludwig MS, Robatto FM, Sly PD, Browman M, Bates JHT, Romero PV. Histamine-induced constriction of canine peripheral lung: an airway or tissue response? $J \mathrm{Appl}$ Physiol 1991; 71: 287-293.

8. Nijkamp FP, Van Der Linde HJ, Folkerts G. Nitric oxide synthesis inhibitors induce airway hyperresponsiveness in the guinea pig in vivo and in vitro. Am Rev Respir Dis 1993; 148: 727-734.

9. Fedan JS, Warner TE, Yuan LX, Robinson VA, Frazer DG. Nitric oxide synthase inhibitor and lipopolysaccharide effects on reactivity of guinea pig airways. $J$ Pharmacol Exp Ther 1995; 272: 1141-1150.

10. Kips JC, Lefebvre RA, Peleman RA, Joos GF, Pauwels RA. The effect of a nitric oxide synthase inhibitor on the modulation of airway responsiveness in rats. Am J Respir Crit Care Med 1995; 151: 1165-1169.

11. Figini M, Ricciardolo FLM, Javdan P, et al. Evidence that epithelium-derived relaxing factor released by bradykinin in the guinea pig trachea is nitric oxide. Am J Respir Crit Care Med 1996; 153: 918-923.

12. Tsukagoshi H, Robbins RA, Barnes PJ, Chung KF. Role of nitric oxide and superoxide anions in interleukin-1 $\beta$ induced airway hyperresponsiveness to bradykinin. $\mathrm{Am} \mathrm{J}$ Respir Crit Care Med 1994; 150: 1019-1025.

13. Ricciardolo FLM, Nadel JA, Yoishihara S, Geppetti P. Evidence for reduction of bradykinin-induced broncho- constriction in guinea-pigs by release of nitric oxide. $\mathrm{Br} \mathrm{J}$ Pharmacol 1994; 113: 1147-1152.

14. Ludwig MS, Dreshaj I, Solway J, Munoz A, Ingram RH Jr. Partitioning of pulmonary resistance during constriction in the dog: effects of volume history. $J$ Appl Physiol 1987; 62: 807-815.

15. Ray NJ, Jones AJ, Keen P. Morphine, but not sodium cromoglycate, modulates the release of substance $\mathrm{P}$ from capsaicin-sensitive neurons in the rat trachea in vitro. $\mathrm{BrJ}$ Pharmacol 1991; 102: 797-800.

16. Miura M, Belvisi MG, Barnes PJ. Modulation of nonadrenergic noncholinergic neural bronchoconstriction by bradykinin in anesthetized guinea pigs in vivo. J Pharmacol Exp Ther 1994; 268: 482-486.

17. Abraham WM, Burch RM, Farmer SG, Sielczak MW, Ahmed A, Cortes A. A bradykinin antagonist modifies allergen-induced mediator release and late bronchial responses in sheep. Am Rev Respir Dis 1991; 143: 787-796.

18. Akbary AM, Wirth KJ, Scholkens BA. Efficacy and tolerability of icatibant (Hoe 140) in patients with moderately severe chronic bronchial asthma. Immunopharmacology 1996; 33: 238-242.

19. Mak JCW, Barnes PJ. Autoradiographic visualization of bradykinin receptors in human and guinea pig lung. Eur $J$ Pharmacol 1991; 194: 37-43.

20. Farmer SG, Burch RM, Meeker SA, Wilkins DE. Evidence for a pulmonary $\mathrm{B}_{3}$ bradykinin receptor. Mol Pharmacol 1989; 36: 1-8.

21. Wirth KJ, Gehring D, Scholkens BA. Effect of Hoe 140 on bradykinin-induced bronchoconstriction in anesthetized guinea pigs. Am Rev Respir Dis 1993; 148: 702-706.

22. Bao G, Qadri F, Stauss B, Strauss H, Gohlke P, Unger T. Hoe 140, a new highly potent and long-acting bradykinin antagonist in conscious rats. Eur J Pharmacol 1991; 200: 179-182.

23. Moncada S, Higgs A. The L-arginine-nitric oxide pathway. N Engl J Med 1993; 329: 2002-2012.

24. Furchgott RF. The discovery of endothelium-derived relaxing factor and its importance in the identification of nitric oxide. JAMA 1996; 276: 1186-1188.

25. Reif DW, McCreedy SA. $N$-nitro-L-arginine and $N$-monomethyl-L-arginine exhibit a different pattern of inactivation toward the three nitric oxide synthases. Arch Biochem Biophysics 1995; 320: 170-176.

26. Forstermann U, Schmidt HHHW, Pollock JS, et al. Isoforms of nitric oxide synthase: characterization and purification from different cell types. Biochem Pharmacol 1991; 42: 1849-1857.

27. Ree DD, Palmer RMJ, Schulz R, Hodson HF, Moncada S. Characterization of three inhibitors of endothelial nitric oxide synthase in vitro and in vivo. Br J Pharmacol 1990; 101: 746-752.

28. Belvisi MG, Miura M, Stretton D, Barnes PJ. Endogenous vasoactive intenstinal peptide and nitric oxide modulate cholinergic neurotransmission in guinea-pig trachea. Eur J Pharmacol 1993; 231: 97-102.

29. Kobzik L, Bredt DS, Lowenstein CJ, et al. Nitric oxide synthase (NOS) in human and rat lung: immunocytochemical and histochemical localization. Am J Respir Cell Mol Biol 1993; 9: 371-377.

30. Barnes PJ. Neural control of human airways in health and disease. Am Rev Respir Dis 1986; 134: 1289-1314. 